\title{
Analysis of 4G LTE Indoor Networks Performance with Networks in the Engineering Faculty G5 Building Universitas Muhammadiyah Yogyakarta
}

\author{
Widyasmoro $^{* 1}$, Ramadoni Syahputra ${ }^{1}$, Kunnu Purwanto ${ }^{1}$, Dedy Prasetiyo ${ }^{1}$, Yessi Jusman ${ }^{1}$ \\ ${ }^{1}$ Department of Electrical Engineering, Faculty of Engineering, Universitas Muhammadiyah Yogyakarta \\ Bantul 55183 Daerah Istimewa Yogyakarta, Indonesia \\ *Corresponding author, e-mail: widyasmoro@umy.ac.id
}

\begin{abstract}
Analysis of the performance of the LTE network with WiFi networks was carried out in the G5 building of the Faculty of Engineering, University of Muhammadiyah Yogyakarta, which is the building of the Faculty of Engineering Laboratory. This research was conducted by comparing the LTE network with indoor or indoor WiFi networks, measuring these two networks using the Network Analyzer and Wifi Analyzer application to obtain information on signal quality data based on KPI and TIPHON standardization, which shows RSRP, RSRQ, and Throughput values through measurement using the Network Analyzer and Wifi Analyzer application. From the results of research that has been done shows that the G5 building has a WiFi internet network that is superior to the LTE internet network. The overall condition of the Wifi network is in very good condition and is stable for each floor. While the LTE network even though it has increased conditions on the second floor but overall is in a bad condition to normal. The LTE network has an RSRP value with an average of $-143 \mathrm{dBm}$, while a WiFi network with an average of $-90 \mathrm{dBm}$. Then the LTE network has an RSRQ value with an average of $-13 \mathrm{dBm}$, while the Wifi network with an average of $-15 \mathrm{dBm}$. For LTE network throughput it has an average max. ping by $50.9 \mathrm{~ms}$ and min. ping is $864.5 \mathrm{~ms}$, while WiFi networks have max average. ping by $24.3 \mathrm{~ms}$ and min. ping of $144.5 \mathrm{~ms}$. From the results of these data show that the G5 Building has a good WiFi network and is superior to the LTE network.
\end{abstract}

Keywords: LTE, WiFi, RSRP, RSRQ, Throughput

\section{Introduction}

Development in field technology Information communication has now led the use of wireless or known technology with the term Wireless technology. Starts with Radio Call technology, then telephone cordless or mobile and growing up to Bluetooth technology .Today's human life is influenced by technology like cellphones to communicate. Humans in communication should be pay good attention to ethics sothe communication can run smoothly and effective. As a perfect religion of Islam teach in great detail how humans can communicate well with each other. The need for communication is not only for telecommunications network users (handphone) which is outside the area, but alsoapplies to indoor areas, such as: buildings, offices, schools, and so on. Building Coverage System is a system with mounted transmitter and receiver devices in the indoor area with the aim to be able to serve the need for telecommunications in the area. The quality of an indoor network is determined by how muchgood performance on LTE (Long Term Evolution) and WiFi (Wireless Fidelity) networks, where both networks are equally technology Wireless .Thenf orto fix and improve the quality of internet connection services at in the building infrastructure needs to be built WiFi network that has a small Loss. So traffic capacity needs can be served with maximum.

As for several previous related studies which is used in various applications. This matter can be 
seen in existing studies as:

Fazliadi Rahmatillah, et al (2015), in his research on "Performance Analysis Traffic Offload Data Between 3G and Wifi ". OnThis research was conducted an analysis and simulation of traffic Data Offload between $3 \mathrm{G}$ and WiFi with using MATLAB R2013b Software. Analysis done by observing the Received parameters Signal Strength, User Handover, and Drop User, Handover Delay, and Throughput [1].

Indra Surjati, Henry Candra, Agung Prabowo, lecturers of the Department of Electrical Engineering-FTI Trisakti University (2007), in his research regarding "Wifi Network Integration System Analysis With an Indoor GSM Network on the Basement Floor Jakarta Convention Center Convention Center ". Research it discusses the WiFi network integrated into the cellular telephone network GSM $1800 \mathrm{MHz}$, with the aim of finding a solution easy and inexpensive in building networks internet and telecommunications [2].

Lutfi Mahfuzh.et al (2016), with his research on "Planning Analysis LTE-Advance Network Integration with Wifi802.11n Existing on the Side of Coverage ". This research conducted at public lecture buildings Telkom University which consists of 10 floors. Thing this is because there are too many students, lecturers as well as the Telkom University community located atin the building gets acceptance the signal in the indoor area of the building becomes not good. To resolve the issue need to do the Long Term network design Evolution-Advance (LTE-A) and WiFi 802.11n [3].

Puspitasari and Pulungan (2014), with his research on "Placement Optimization Access Point Positionon the WiFi Network Using the Simulated Annealing Method ". On this research is to measure signal strength from the access point to the receiver in the lecturers' room and lobby of the 2nd floor of STMIK building AMIKOM Yogyakarta measured using insider application and generate RSSI values (Received Signal Strength Indication) of a transmitter against the receiver. In measured too used Line of sight (LOS) propagation andPropagation of Non Line Of Sight (NLOS) [4].

Cahyaningtyas and Silistyo (2017), with his research on "Radio Frequency Analysis Wireless Fidelity (WiFi) on Network Performance UKSW WiFi FTI (UKSW's WiFi FTI Case Study)". This research was conducted to analyze performance WiFi network at the UKSW FTI Building through WiFi channel placement then measures signal reception at several points directly then theoretically calculated using OneSlope Model [5].
Pipit Wulandari, et al (2017), this study discusses "Monitoring and Analysis of QoS (Quality Of Service) Internet Networks in Buildings KPA Sriwijaya State Polytechnic with Methods Drive Test ". The study looked at network quality the internet by direct measurement in real time using the method Drive Test by using one of the providers as performance material [6].

Garnis, Suroso, and Soim (2017), this study discuss about "Signal Quality Assessment and the Position of the Wifi Access Point with the RSSI Method in the KPA Building of Sriwijaya State Polytechnic ". On this study measured signal strength forobtain the estimated distance using the method Received Signal Strength Indicator (RSSI). Measurements made involve calibration RSI value for each reference node [7].

Wulandari Rika (2016), this study discusses regarding "QoS Analysis (Quality Of Service) On Internet Network (Case Study: Upt Technical Test Workshop Jampang Kulon Mining - LIPI) ". This method uses the QoS Model Monitoring which is a method of measurement about how good the network is and is a business to define the characteristics and nature of a service. The QoS Monitoring Model consists of monitoring application, QoS monitoring, and monitored objects [8].

\section{Methods}

\section{II.1. Research Sites}

The location chosen as a place of research and data collection is the G5 Faculty Building Engineering of Muhammadiyah University Yogyakarta. The object of research is LTE network quality and WiFi networks, comparison of the two networks the. Figure 1 shows an image of a location map UMY G5 Building.

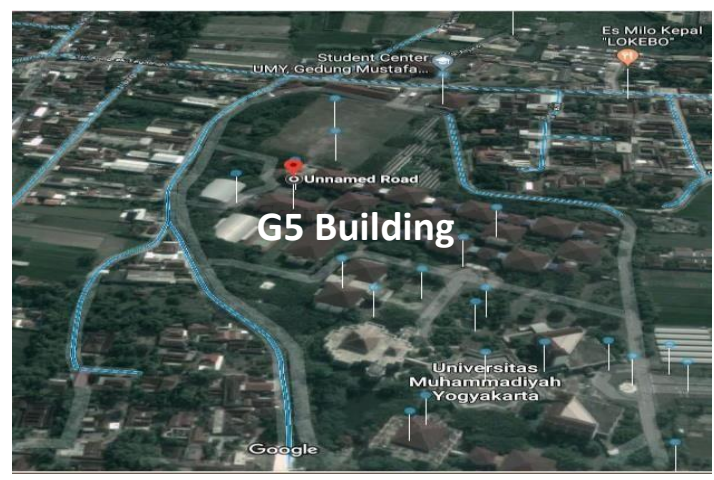

Fig. 1. Map of the G5 Building Universitas Muhammadiyah Yogyakarta (Source: Google Maps) 


\section{II.2. Research Procedure}

The research procedures in designing this system. Figure 2 shows the flowchart for the whole system.

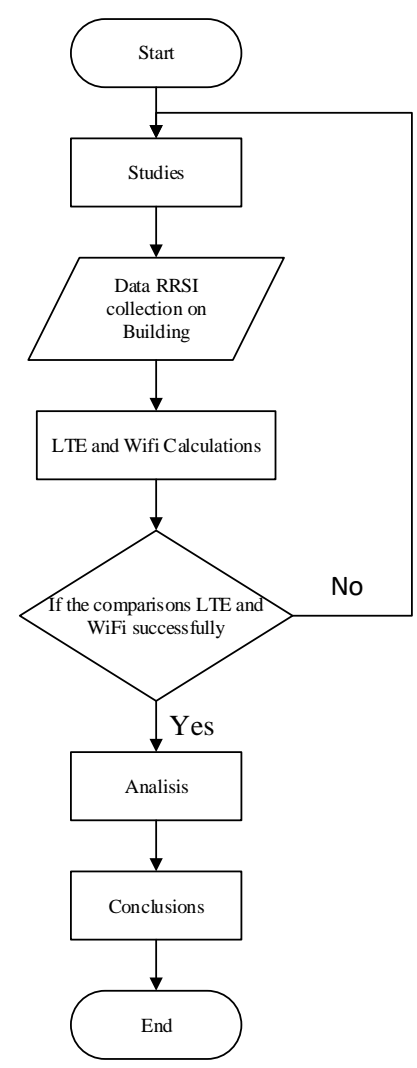

Fig. 2. Flowchart

\section{II.3. Tahapan Penelitian}

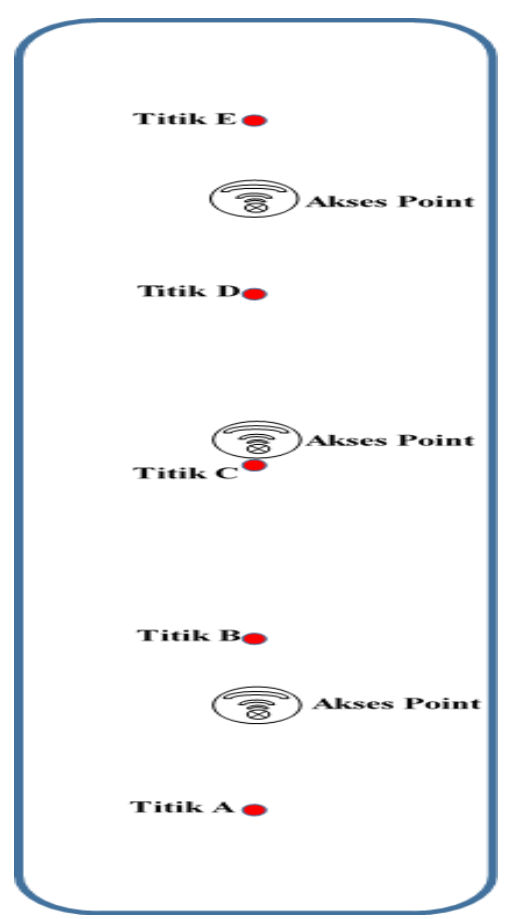

Fig. 3. Points for Measuring Hallway G5
The research carried out has several stages namely by analyzing signal indoor quality LTE network, WiFi network signal quality, and comparison found in the two the networks. The stages carried out are as follows:

1. Determine the points on the building

In determining these points, aim to get enough data, which point it can represent the LTE network area and WiFi network inside the building point placement. This point adjusts the condition or shape of the building in order to cover all areas in the building on each floor. The number of points to be used also adjusted to the area to be measured in order effective measurement results obtained and maximum. Figure 3 shows the dots Hallway measurement of G5 Building.

\section{Measurement of Radio Frequency (RF)}

Radio Frequency is one electromagnetic frequency waves located at frequencies from $3 \mathrm{kHz}$ to $300 \mathrm{GHz}$. Result of this measurement aims to determine the strength signal both transmit power and accepting power are generated by LTE networks and WiFi networks. The units used to assess the signal Strength is $\mathrm{dBm}$ which is a unitstrong mobile signal that shows signal reception from BTS (Base Transceiver Station) closest operator. Table I shows classification of signal strength based on RSSI value (Received Signal Strength Indicator).

TABLE I

SIGNAL STRENGTH CLASSIFICATION

\begin{tabular}{ccc}
\hline \hline Power (Watt) & $\begin{array}{c}\text { Range } \\
\text { RSRP } \\
\text { (dBm) }\end{array}$ & Category \\
\hline $0.01 n W \geq x$ & $-80 \leq \mathrm{x}$ & Very Good \\
$0.001 n W$ to $0.01 n W$ & -90 to -80 & Good \\
$0.1 p W$ to $0.001 n W$ & -100 to -90 & Normal \\
$0.001 p W$ to $0.1 p W$ & -120 to -100 & Bad \\
$0.001 p W \geq x$ & $-120 \geq \mathrm{x}$ & Very Bad \\
\hline \hline
\end{tabular}

TABLE II

RSRP CLASSIFICATION

\begin{tabular}{ccc}
\hline \hline Power (Watts) & $\begin{array}{c}\text { Range } \\
\text { RSRP } \\
\text { (dBm) }\end{array}$ & Category \\
\hline $0.01 \mathrm{nW} \geq \mathrm{x}$ & $-80 \leq \mathrm{x}$ & Very Good \\
$0.001 \mathrm{nW}$ to $0.01 \mathrm{nW}$ & -90 to -80 & Good \\
$0.1 \mathrm{pW}$ to $0.001 \mathrm{nW}$ & -100 to -90 & Normal \\
$0.001 \mathrm{pW}$ to $0.1 \mathrm{pW}$ & -120 to -100 & Bad \\
$0.001 \mathrm{pW} \geq \mathrm{x}$ & $-120 \geq \mathrm{x}$ & Very Bad \\
\hline \hline
\end{tabular}


RRSRP (Reference Signal Received Power) is a type of LTE Signal Measurement which where as an indicator of average power on are source element that carries a reference signal in a subcarrier called RSRP. Besides RSRP as a parameter of the received LTE power signalby the user in a certain frequency. Table II shows the results of the RSRP classification.

TABLE III

RSRP CLASSIFICATION

\begin{tabular}{ccc}
\hline \hline Power (Watts) & $\begin{array}{l}\text { Range } \\
\text { RSRP } \\
\text { (dBm) }\end{array}$ & Category \\
\hline $0.01 \mathrm{nW} \geq \mathrm{x}$ & $-80 \leq \mathrm{x}$ & Very Good \\
$0.001 \mathrm{nW}$ to $0.01 \mathrm{nW}$ & -90 to -80 & Good \\
$0.1 \mathrm{pW}$ to $0.001 \mathrm{nW}$ & -100 to -90 & Normal \\
$0.001 \mathrm{pW}$ to $0.1 \mathrm{pW}$ & -120 to -100 & Bad \\
$0.001 \mathrm{pW} \geq \mathrm{x}$ & $-120 \geq \mathrm{x}$ & Very Bad \\
\hline \hline
\end{tabular}

RSRQ (Reference Signal Received Quality) is a type of measurement of the LTE signal which as parameters which to determine the quality of the signal received called RSRQ. A part from that RSRQ as a ratio between the number of N, RSRP to RSSI (Received Signal Strength Indication). Table III shows the results of the RSRQ value classification.

TABLE IV.

RSRQ VALUE CLASSIFICATION

\begin{tabular}{ccc}
\multicolumn{4}{c}{ RSRQ VALUE CLASSIFICATION } \\
\hline \hline & $\begin{array}{l}\text { Range } \\
\text { RSRP } \\
\text { Power (Watts) }\end{array}$ & Category \\
& $-9 \leq \mathrm{x}$ & Very Good \\
& -10 to -9 & Good \\
$0.1 \mathrm{~mW}$ to $0.8 \mathrm{~mW}$ & -15 to -10 & Normal \\
$0.03 \mathrm{~mW}$ to $0.1 \mathrm{~mW}$ & -19 to -15 & Bad \\
$0.012 \mathrm{~mW}$ to $0.03 \mathrm{~mW}$ & $-20 \geq \mathrm{x}$ & Very Bad \\
$0.010 \mathrm{~mW} \geq \mathrm{x}$ & & \\
\hline \hline
\end{tabular}

SNR (Signal Noise Ratio) or SINR is a ratio between the average power received with average interference and noise. The Signal Noise Ratio value is used for know the quality of the connection line. The greater it is the value of an SNR, the higher the path quality that means when the SNR gets bigger then the path used for data communication traffic and signals at high speeds.

After all the data will be collected calculations using the formula. Table IV shows the classification of resource blocks used and the calculation formula.
TABLE V

RESOURCE BLOCK CLASSIFICATION (SOURCE: ANRItsu Lte Resource Guide)

\begin{tabular}{ccc}
\hline \hline $\begin{array}{c}\text { Channel Bandwith } \\
(\mathrm{MHz})\end{array}$ & $\begin{array}{c}\text { Maximum } \\
\text { Number of } \\
\text { Resource } \\
\text { Blocks }\end{array}$ & $\begin{array}{c}\text { Maximum } \\
\text { Occupied } \\
\text { Bandwith (MHz) }\end{array}$ \\
\hline 1.4 & 6 & 1.08 \\
3 & 15 & 2.7 \\
5 & 25 & 4.5 \\
10 & 50 & 9.0 \\
15 & 75 & 13.5 \\
20 & 100 & 18.0 \\
\hline \hline
\end{tabular}

3. Measurement of LTE network throughput and WiFi network

Throughput is the speed (rate) of transf ereffective data upload and download paths, or you can also called the average speed of data received by a node (EU to EnodeB), incertain time lapse of observation. Throughput is the actual bandwidth right then and there we are connecting. Unit of which has the same as the bandwidth that is bps. Measurements to be carried out viz Measurement of Packet Loss and Delay (Latency).

Packet Loss is the number of packets lost on a packet network caused by collision, its full capacity network, and packet loss caused by endless TTL (Time To Live) packages. Delay (Latency) is the time delay when a packet is caused by the transmission process from one point to another point that becomes his destination. Table $\mathrm{V}$ shows the results of the classification assessment Throughput

TABLE VI

Classification OF Throughrut AsSESMENT (SOURCE: THIPON)

\begin{tabular}{cccc}
\hline \hline Category & $\begin{array}{c}\text { Packet } \\
\text { Loss }\end{array}$ & $\begin{array}{c}\text { Delay } \\
\text { (Latency) }\end{array}$ & Indeks \\
\hline Very & 0 & $\mathrm{X}<150 \mathrm{~ms}$ & 4 \\
Good & & $\begin{array}{c}150 \mathrm{~ms} \mathrm{~s} / \mathrm{d} \\
300 \mathrm{~ms}\end{array}$ & 3 \\
Good & 3 & $\begin{array}{c}300 \mathrm{~ms} \mathrm{~s} / \mathrm{d} \\
450 \mathrm{~ms}\end{array}$ & 2 \\
Normal & 15 & $\mathrm{X}>450 \mathrm{~ms}$ & 1 \\
Bad & 25 &
\end{tabular}

4. The Classification used for measurement RSSI, RSSP, RSRQ, and Delay (Latency)

The creation of this classification table is required for makes it easy to compare networks LTE internet with WiFi internet network. Following is Table VI which shows the classification radio frequency assessment. 
TABLE VII

RADIO FREQUENCY ASSESMENT CLASSIFICATION

\begin{tabular}{cccccc}
\hline \hline \multirow{2}{*}{ Color } & Indeks & Classification & RSSI (dBm) & RSRP $(\mathrm{dBm})$ & \multirow{2}{*}{ RSRQ (dB) } \\
& Number & Very good & $\mathrm{X}>-70$ & $\mathrm{X} \geq-80$ & $\mathrm{X} \geq-9$ \\
& 5 & Good & -70 to -85 & -80 to -90 & -9 to -10 \\
& 4 & Normal & -86 to -100 & -90 to -100 & -10 to -15 \\
3 & Bad & -100 to 110 & -100 to -120 & -15 to 19 \\
& 2 & Very bad & $\mathrm{X}<-110$ & $\mathrm{X} \leq-120$ & $\mathrm{X} \leq-20$ \\
\hline
\end{tabular}

TABLE VIII

\begin{tabular}{ccc}
\multicolumn{3}{c}{ Data MeAsurements Results } \\
\hline \multirow{2}{*}{ Point } & $\begin{array}{c}\text { Packet } \\
\text { Loss }\end{array}$ & $\begin{array}{c}\text { Delay } \\
\text { (Latency) }\end{array}$ \\
\cline { 2 - 3 } & LTE & $\mathrm{WiFi}$ \\
\hline A & -118 & -49 \\
B & -117 & -56 \\
C & -115 & -58 \\
D & -118 & -56 \\
E & -113 & -73 \\
\hline
\end{tabular}

TABLE IX

CALCULATION RESUlTS OF RSRP AND RSRQ

\begin{tabular}{ccccccc}
\hline \hline & \multicolumn{2}{c}{ RSSI $(\mathrm{dBm})$} & \multicolumn{2}{c}{ RSRP $(\mathrm{dBm})$} & \multicolumn{2}{c}{$\operatorname{RSRQ}(d B)$} \\
\cline { 2 - 7 } Point & LTE & WiFi & LTE & WiFi & LTE & WiFi \\
& & & & & & \\
\hline A & -118 & -49 & -148 & -79 & -12.5 & -16.1 \\
B & -117 & -56 & -147 & -56 & -12.6 & -14.8 \\
C & -115 & -58 & -145 & -88 & -12.6 & -15.2 \\
D & -118 & -56 & -148 & -86 & -12.5 & -14.8 \\
E & -113 & -73 & -143 & -103 & -12.6 & -14.1 \\
Average & -116 & -58 & -146 & -88 & -12.6 & -15 \\
\hline \hline
\end{tabular}

TABLE X

Classification of Calculation Results RSRP AND RSRQ

\begin{tabular}{|c|c|c|c|c|c|c|}
\hline \multirow{2}{*}{ Point } & \multicolumn{2}{|c|}{ RSSI (dBm) } & \multicolumn{2}{|c|}{$\operatorname{RSRP}(\mathrm{dBm})$} & \multicolumn{2}{|c|}{$R S R Q(d B)$} \\
\hline & LTE & WiFi & LTE & WiFi & LTE & WiFi \\
\hline$\overline{\mathrm{A}}$ & Very Bad & Very Good & Very Bad & Very Good & Normal & $\mathrm{Bad}$ \\
\hline B & Very Bad & Very Good & Very Bad & Good & Normal & Normal \\
\hline $\mathrm{C}$ & Very Bad & Very Good & Very Bad & Good & Normal & $\mathrm{Bad}$ \\
\hline D & Very Bad & Very Good & Very Bad & Good & Normal & $\mathrm{Bad}$ \\
\hline $\mathrm{E}$ & Very Bad & Good & Very Bad & $\mathrm{Bad}$ & Normal & Normal \\
\hline Average & Very Bad & Very Good & Very Bad & Good & Normal & Normal \\
\hline
\end{tabular}

\section{Results}

\section{III.1. Data Collection on the Ground Floor}

Based on the results of Table VI shows that there are differences in RSSI values between networks LTE with a WiFi network. Difference which is obtained can be said to be almost twice the network WiFi is superior to LTE networks. After obtain primary data hence forth calculate RSRP and RSRQ values. Table VIII shows the results of RSRP and RSRQ calculations and Table IX shows the classification of results RSRP and RSRQ calculations.

Based on the results of Table 8 which shows the results of RSRP and RSRQ calculations, so we get a classification graph that is shown in Figure 4. 
a) Measurements of Delay (Latency) and Packet Loss

Measurements made in this section vizusing Net Analyzer software, where this software has Ping Tools. This tool can used to know Delay and Packet Loss incurred. Ping is done from the starting address mobile device (10.235.165.217) to the destination address www.google.com (172.217.26.78). Ping that done as much as 20 times / 20 packets shipped. Table $\mathrm{X}$ shows the measurement of delayand packet loss and classification in Table XI for Ground Floor.

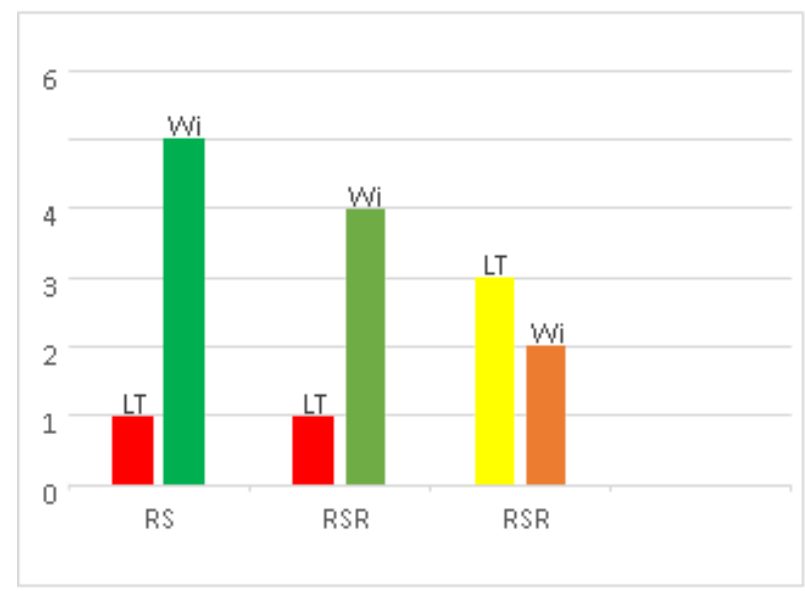

Fig. 4. Graph classification of RSRP calculation results and RSRP

TABLE XI

Measurement of Delay and Packet Loss

\begin{tabular}{|c|c|c|c|c|c|c|c|}
\hline \multirow{3}{*}{ Point } & \multicolumn{6}{|c|}{ Delay (Latency) with units (ms) } & \multirow{3}{*}{ Packet Loss } \\
\hline & \multicolumn{2}{|c|}{ Max.Ping } & \multicolumn{2}{|c|}{ Min.Ping } & \multicolumn{2}{|c|}{ Median Ping } & \\
\hline & LTE & WiFi & LTE & $\mathrm{WiFi}$ & LTE & WiFi & \\
\hline $\mathrm{A}$ & 92.0 & 28.3 & 1733.1 & 71.7 & 311.6 & 45.5 & $\begin{array}{c}9 \text { (LTE) } 1 \\
(\mathrm{WiFi})\end{array}$ \\
\hline B & 57.5 & 37.7 & 1990.6 & 86.6 & 88.3 & 51.5 & 4 (LTE) \\
\hline $\mathrm{C}$ & 64.0 & 26.3 & 474.0 & 56.7 & 145.8 & 48.0 & 0 \\
\hline $\mathrm{D}$ & 55.1 & 27.8 & 358.7 & 90.7 & 102.9 & 45.1 & 0 \\
\hline $\mathrm{E}$ & 49.4 & 37.2 & 274.1 & $\begin{array}{c}126 . \\
8\end{array}$ & 63.0 & 50.4 & 0 \\
\hline
\end{tabular}

TABLE XII

DELAY AND PACKeT LOSS ClassiFiCATIONS

\begin{tabular}{|c|c|c|c|c|c|c|c|}
\hline \multicolumn{8}{|c|}{ Delay (Latency) with units (ms) } \\
\hline \multirow{2}{*}{ Points } & \multicolumn{2}{|c|}{ Max.Ping } & \multicolumn{2}{|c|}{ Min.Ping } & \multicolumn{2}{|c|}{ Median Ping } & \multirow{2}{*}{ Packet Loss } \\
\hline & LTE & $\mathrm{WiFi}$ & LTE & WiFi & LTE & $\mathrm{WiFi}$ & \\
\hline $\mathrm{A}$ & Very Good & Very Good & $\mathrm{Bad}$ & Very Good & Normal & Very Good & Normal \\
\hline $\mathrm{B}$ & Very Good & Very Good & $\mathrm{Bad}$ & Very Good & Very Good & Very Good & Very Good \\
\hline $\mathrm{C}$ & Very Good & Very Good & $\mathrm{Bad}$ & Very Good & Very Good & Very Good & 0 \\
\hline $\mathrm{D}$ & Very Good & Very Good & Normal & Good & Very Good & Very Good & 0 \\
\hline $\mathrm{E}$ & Very Good & Very Good & Good & Very Good & Very Good & Very Good & 0 \\
\hline
\end{tabular}


Based on the data shown in Table $\mathrm{X}$ and Table XI measurements that have been obtained well Delay and Packet Loss indicate that WiFi networks are still superior to networks LTE. In the second best condition (max. Ping) network in classification is very good, but on the worst condition (min. ping) then it appears that LTE networks are in the bad classification, while the WiFi network remains in the classification Very Good.

\section{III.2. Data Collection on the First Floor}

Based on the results of Table XII shows that there is a difference in RSSI values between LTE networks with a WiFi network. Difference is obtained it can also be said to be almost twice the WiFi network superior to LTE networks, but value The resulting RSSI is slightly experienced decrease. After obtaining primary data then calculate the value of RSRP and RSRQ.Table XIII shows the results of calculations on values RSRP and RSRQ, as well as Table XIII show the results of the classification of RSRP and RSRQ calculation.

TABLE XIII

Data MEASUREMENT Results

\begin{tabular}{ccc}
\hline \hline Point & $\begin{array}{c}\text { Packet } \\
\text { Loss }\end{array}$ & $\begin{array}{c}\text { Delay } \\
\text { (Latency) }\end{array}$ \\
\cline { 2 - 3 } & LTE & WiFi \\
\hline A & -114 & -78 \\
B & -108 & -62 \\
C & -118 & -64 \\
D & -114 & -63 \\
E & -116 & -65 \\
\hline \hline
\end{tabular}

TABLE XIV

CALCULATION RESULTS RSRP AND RSRQ

\begin{tabular}{ccccccc}
\hline \hline & \multicolumn{2}{c}{ RSSI $(\mathrm{dBm})$} & \multicolumn{2}{c}{ RSRP $(\mathrm{dBm})$} & \multicolumn{2}{c}{$\operatorname{RSRQ}(d B)$} \\
\cline { 2 - 7 } Point & LTE & WiFi & LTE & WiFi & LTE & WiFi \\
\hline A & -114 & -78 & -144 & -108 & -12.6 & -13.8 \\
B & -108 & -62 & -138 & -92 & -12.8 & -14.8 \\
C & -118 & -64 & -148 & -94 & -12.5 & -14.7 \\
D & -114 & -63 & -144 & -93 & -12.6 & -14.8 \\
E & -116 & -65 & -146 & -95 & -12.6 & -14.6 \\
Average & -114 & -66 & -144 & -96 & -12.6 & -14.5 \\
\hline \hline
\end{tabular}

TABLE XV

Classification of CALCUlation Results RSRP AND RSRQ

\begin{tabular}{ccccccc}
\hline \multirow{2}{*}{ Point } & \multicolumn{2}{c}{ RSSI $(\mathrm{dBm})$} & \multicolumn{2}{c}{ RSRP $(\mathrm{dBm})$} & \multicolumn{2}{c}{$\operatorname{RSRQ}(d B)$} \\
\cline { 2 - 7 } & LTE & WiFi & LTE & WiFi & LTE & \multirow{2}{*}{ WiFi } \\
\hline A & Very Bad & Good & Very Bad & Bad & Normal & Normal \\
B & Bad & Very Good & Very Bad & Normal & Normal & Normal \\
C & Very Bad & Very Good & Very Bad & Normal & Normal & Bad \\
D & Very Bad & Very Good & Very Bad & Normal & Normal & Bad \\
E & Very Bad & Good & Very Bad & Normal & Normal & Normal \\
Average & Very Bad & Very Good & Very Bad & Normal & Normal & Normal \\
\hline \hline
\end{tabular}


Based on Table XIV which shows the results of the classification of RSRP and RSRQ calculations then we get the graph shown in Figure 5.

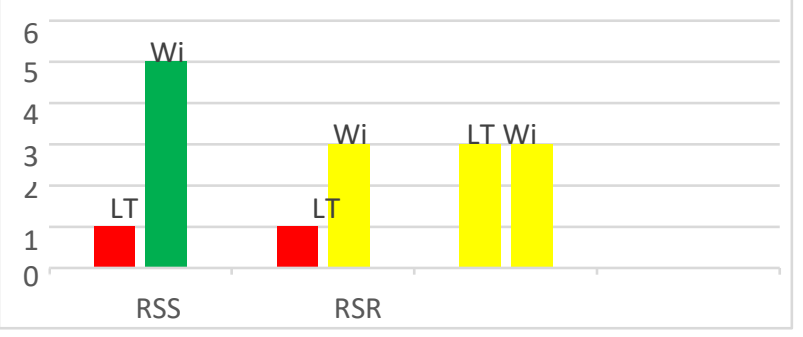

Fig. 5. Graph classification of RSRP calculation results and RSRQ a) Measurement of Delay (Latency) and Packet

Loss

Measurements made in this section namely using the Net Analyzer software, where this software has Ping Tools. This tool can used to know Delay and Packet Loss incurred. Ping is done from the starting address mobile device $(10.235 .165 .217)$ to the destination address www.google.com (172.217.26.78). Ping that done as much as 20 times / 20 packets shipped. . Table XV shows the measurements delay and packet loss and classification in Table XVI for the First Floor.

TABLE XVI

Measurement Delay AND PaCKet Loss

\begin{tabular}{|c|c|c|c|c|c|c|c|}
\hline \multicolumn{8}{|c|}{ Delay (Latency) with units (ms) } \\
\hline \multirow{2}{*}{ Point } & \multicolumn{2}{|c|}{ Max.Ping } & \multicolumn{2}{|c|}{ Min.Ping } & \multicolumn{2}{|c|}{ Median Ping } & \multirow{2}{*}{ Packet Loss } \\
\hline & LTE & WiFi & LTE & WiFi & LTE & WiFi & \\
\hline $\mathrm{A}$ & 92.0 & 28.3 & 1733.1 & 71.7 & 311.6 & 45.5 & 9 (LTE) 1 (WiFi) \\
\hline B & 57.5 & 37.7 & 1990.6 & 86.6 & 88.3 & 51.5 & 4(LTE) \\
\hline $\mathrm{C}$ & 64.0 & 26.3 & 474.0 & 56.7 & 145.8 & 48.0 & 0 \\
\hline $\mathrm{D}$ & 55.1 & 27.8 & 358.7 & 90.7 & 102.9 & 45.1 & 0 \\
\hline $\mathrm{E}$ & 49.4 & 37.2 & 274.1 & 126.8 & 63.0 & 50.4 & 0 \\
\hline
\end{tabular}

TABLE XVII

MEASUREMENT OF DELAY AND PACKet Loss

\begin{tabular}{|c|c|c|c|c|c|c|c|}
\hline \multicolumn{8}{|c|}{ Delay (Latency) with units (ms) } \\
\hline \multirow{2}{*}{ Point } & \multicolumn{2}{|c|}{ Max.Ping } & \multicolumn{2}{|c|}{ Min.Ping } & \multicolumn{2}{|c|}{ Median Ping } & \multirow{2}{*}{ Packet Loss } \\
\hline & LTE & WiFi & LTE & WiFi & LTE & WiFi & \\
\hline $\mathrm{A}$ & Very Good & Very Good & $\mathrm{Bad}$ & Very Good & Normal & Very Good & Normal \\
\hline B & Very Good & Very Good & $\mathrm{Bad}$ & Very Good & Very Good & Very Good & Very Good \\
\hline $\mathrm{C}$ & Very Good & Very Good & $\mathrm{Bad}$ & Very Good & Very Good & Very Good & 0 \\
\hline $\mathrm{D}$ & Very Good & Very Good & Normal & Good & Very Good & Very Good & 0 \\
\hline $\mathrm{E}$ & Very Good & Very Good & Good & Very Good & Very Good & Very Good & 0 \\
\hline
\end{tabular}

TABLE XVIII

DAta MEASUREMENT Results

\begin{tabular}{|c|c|c|}
\hline \multirow{2}{*}{ Point } & $\begin{array}{c}\text { Packet } \\
\text { Loss }\end{array}$ & $\begin{array}{c}\text { Delay } \\
\text { (Latency) }\end{array}$ \\
\hline & LTE & WiFi \\
\hline $\mathrm{A}$ & -114 & -78 \\
\hline B & -108 & -62 \\
\hline $\mathrm{C}$ & -118 & -64 \\
\hline D & -114 & -63 \\
\hline $\mathrm{E}$ & -116 & -65 \\
\hline
\end{tabular}


Based on Tables XV and XVI measurements that have been obtained both delay and Packet Loss shows that a WiFi network superior to LTE networks.

\section{III.3. Data Collection on the Second Floor}

Based on the results of Table XVII shows that existence indicates that it isdifference in RSSI values between LTE networks and WiFi network. On this second floor the RSSI value is onLTE has increased from the classification Very Bad becomes Bad. After obtaining primary data then next calculate the value of RSRP and RSRQ. Table XVIII shows the calculation results on RSRP and RSRQ values, and Table XIX shows the results of the calculation classification RSRP and RSRQ.

Based on Table XIV which shows the results of the classification of RSRP and RSRQ calculations then we get the graph shown in Figure 6 . Measurement of Delay (Latency) and Packet Los.

Measurements made in this section viz using Net Analyzer software, where this software has Ping Tools. This tool can used to determine Delay and Packet Loss that happened. Ping is done from the device's initial address handphone (10.235.165.217) to the destination address www.google.com (172.217.26.78). Ping that done as much as 20 times/20 packets shipped. Table XX shows the measurements delay and packet loss and classification in Table XXI for the Second Floor.

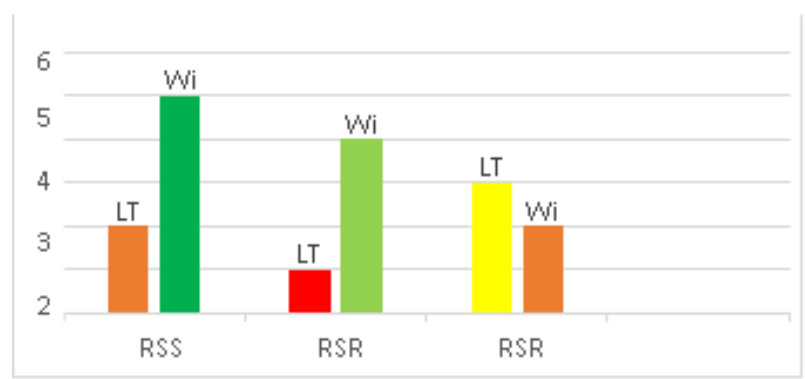

Fig. 6. Graph classification of RSRP calculation results and RSRQ

TABLE XIX

CALCULATION RESULTS OF RSRP AND RSRQ

\begin{tabular}{ccccccc}
\hline \multirow{2}{*}{ Point } & \multicolumn{2}{c}{ RSSI $(\mathrm{dBm})$} & \multicolumn{2}{c}{ RSRP $(\mathrm{dBm})$} & \multicolumn{2}{c}{$R S R Q(d B)$} \\
\cline { 2 - 7 } & LTE & WiFi & LTE & WiFi & LTE & WiFi \\
\hline A & -113 & -72 & -143 & -102 & -12.6 & -14.2 \\
B & -108 & -50 & -138 & -80 & -12.8 & -16 \\
C & -105 & -43 & -135 & -73 & -12.9 & -16.8 \\
D & -103 & -53 & -133 & -83 & -13.1 & -15.7 \\
E & -109 & -61 & -139 & -91 & -12.8 & -14.9 \\
Average & -108 & -56 & -138 & -86 & -12.8 & -15.5 \\
\hline \hline
\end{tabular}

TABLE XX

ClassifCation of Calculation Results RSRP AND RSRQ

\begin{tabular}{ccccccc}
\hline \hline \multirow{2}{*}{ Point } & \multicolumn{2}{c}{ RSSI $(\mathrm{dBm})$} & \multicolumn{2}{c}{ RSRP $(\mathrm{dBm})$} & \multirow{2}{*}{$\operatorname{RSRQ}(\mathrm{dB})$} \\
\cline { 2 - 6 } & LTE & WiFi & LTE & WiFi & \multirow{2}{*}{ LTE } & \multirow{2}{*}{ WiFi } \\
\hline A & Very Bad & Very Good & Very Bad & Very Good & Normal & Bad \\
B & Very Bad & Very Good & Very Bad & Good & Normal & Normal \\
C & Very Bad & Very Good & Very Bad & Good & Normal & Bad \\
D & Very Bad & Very Good & Very Bad & Good & Normal & Bad \\
E & Very Bad & Good & Very Bad & Bad & Normal & Normal \\
Average & Very Bad & Very Good & Very Bad & Good & Normal & Normal \\
\hline \hline
\end{tabular}


TABLE XXI

Measurement of Delay and Packet Loss

\begin{tabular}{|c|c|c|c|c|c|c|c|}
\hline \multicolumn{8}{|c|}{ Delay (Latency) with units (ms) } \\
\hline \multirow{2}{*}{ Point } & \multicolumn{2}{|c|}{ Max.Ping } & \multicolumn{2}{|c|}{ Min.Ping } & \multicolumn{2}{|c|}{ Median Ping } & \multirow{2}{*}{$\begin{array}{c}\text { Packet } \\
\text { Loss }\end{array}$} \\
\hline & LTE & $\mathrm{WiFi}$ & LTE & WiFi & LTE & $\mathrm{WiFi}$ & \\
\hline $\bar{A}$ & 51 & 34.2 & 232.6 & 77.3 & 61.9 & 50.4 & 0 \\
\hline B & 53.1 & 33.9 & 142.4 & 94.7 & 61.6 & 44.5 & 0 \\
\hline $\mathrm{C}$ & 54.1 & 29.2 & 153.5 & 83.2 & 67.9 & 44.8 & 0 \\
\hline $\mathrm{D}$ & 53.4 & 39.8 & 113.2 & 94.7 & 65.7 & 448.4 & 0 \\
\hline E & 58.6 & 25.6 & 125.1 & 77.3 & 73.2 & 44.6 & 0 \\
\hline
\end{tabular}

TABLE XXII

Classification of Delay and Packet Loss

\begin{tabular}{|c|c|c|c|c|c|c|c|}
\hline \multicolumn{8}{|c|}{ Delay (Latency) with units (ms) } \\
\hline \multirow{2}{*}{ Point } & \multicolumn{2}{|c|}{ Max.Ping } & \multicolumn{2}{|c|}{ Min.Ping } & \multicolumn{2}{|c|}{ Median Ping } & \multirow{2}{*}{ Packet Loss } \\
\hline & LTE & WiFi & LTE & WiFi & LTE & WiFi & \\
\hline $\mathrm{A}$ & Very Good & Very Good & Good & Very Good & Very Good & Very Good & Very Good \\
\hline $\mathrm{B}$ & Very Good & Very Good & Very Good & Very Good & Very Good & Very Good & Very Good \\
\hline $\mathrm{C}$ & Very Good & Very Good & Good & Very Good & Very Good & Very Good & Very Good \\
\hline $\mathrm{D}$ & Very Good & Very Good & Very Good & Good & Very Good & Very Good & Very Good \\
\hline $\mathrm{E}$ & Very Good & Very Good & Very Good & Very Good & Very Good & Very Good & Very Good \\
\hline
\end{tabular}

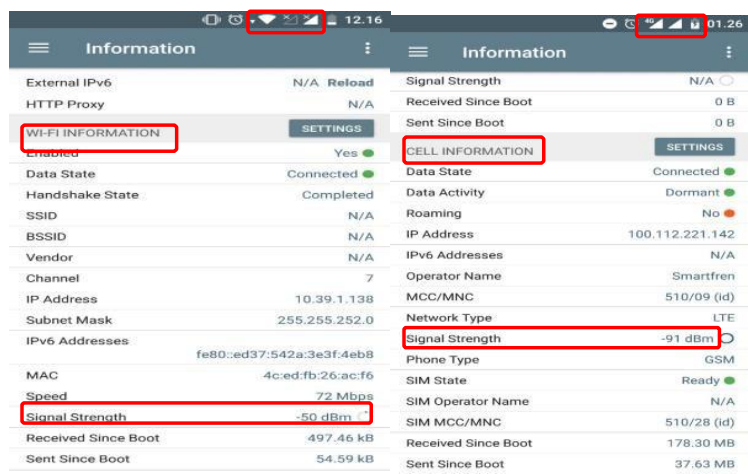

Fig. 7. RSSI LTE network and WiFi measurement results

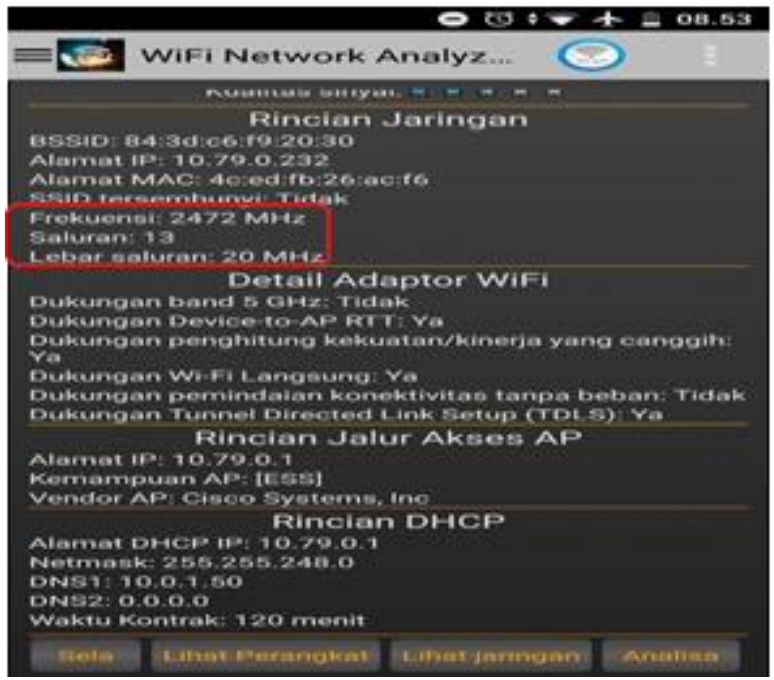

Fig. 8. Bandwith measurement results 
From the measurement that have been obtained both Delay and Packet Loss show that the WiFi network is still superior to that LTE network. In the best condition (max. Ping) both networks in classification are very good. Likewise in the second worst (min. Ping) condition the network is also in very good condition. On the floor These two inputs on the LTE network are in condition better than the floors below.

\section{III.4. Software Measurement Results}

Measurement or data retrieval on this research uses software Network Analyzer and WiFi Analyzer. On software Network Analyzer is used to measure RSSI values and has tools that can be used by the ping utility as a way to find delay. Where as Wifi Analyzer is used to find the frequency and bandwidth used. The following is the screenshot of the software used that is shown in Figure $7-9$
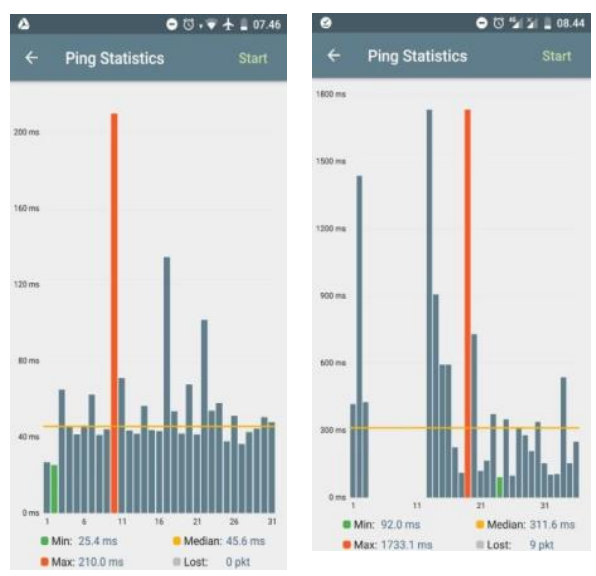

Fig. 9 Delay measurement results with PING

\section{Conclussion}

In this final project research, which becomes the core the discussion is about signal quality generated between LTE and $\mathrm{WiFi}$ at the location indoor building. Based on data and analysis measurements and calculations that have been explained in the previous chapters a few are obtained. The conclusion is:

1. To compare between internet networks LTE with WiFi Network is required appropriate parameters which can be used to assess LTE networks as well as WiFi,that is, such as the Radio Frequency and parameters Throughput.

2. For LTE networks on each floor of the building RSSI and RSRP values are found that increasingly the height of the floor will get better value. Then for the Wifi network on each floor the RSRP building value is obtained that is stable at very good condition.

3. Calculations on the LTE network at each RSRQ building floor values obtained that the higher the floor, the more declining in value. But the decline is happening is insignificant and remains deep normal conditions on all floors. While on the WiFi network the RSRQ value is obtained also stable on each floor or in conditions normal.

4. Calculation of overall throughput on LTE and WiFi networks it was found that both have the same quality or in very good condition. This matter shows that there is a relationship between radio frequency with the throughput of the generated, i.e. the better the RF will be the better the throughput and otherwise.

5. Overall analysis that has been done carried out that between the LTE internet network with a WiFi internet network for location inside the building or indoor, it was found that superior to WiFi internet networks. Thing this is influenced by the quality of the signal received from a stronger $\mathrm{WiFi}$ access point. While signal quality from the LTE internet network on Indoor locations are lower, because there are obstacle like buildings and more distance far from the LTE signal transmitter.

\section{Acknowledgements}

This work was supported by Universitas Muhammadiyah Yogyakarta.

\section{References}

[1] F. Rahmatillah, U. K. Usman, and T. A. Riza, "Analisis Permfomansi Traffic Offload Data Antara 3G dan WiFi dengan Menggunakan Software MATLAB R2013b," Universitas Telkom, Bandung, 2015.

[2] I. Surjati, H. Candra, and A. Prabowo, "Analisis Sistem Integrasi Jaringan WiFi dengan Jaringan GSM Indoor pada Lantai Basement Balai Sidang Jakarta Convention Centre," Universitas Trisakti, Jakarta, 2007.

[3] L. Mahfuzh, H. Wijanto, and U. K. Usman, "Analisis Perencanaan Integrasi Jaringan LTEAdvanced Dengan Wifi 802.11n Existing pada Sisi Coverage," p. 6, 2016.

[4] N. F. Puspitasari and R. Pulungan, "Optimisasi Penempatan Posisi Access Point pada Jaringan WiFi Menggunakan Metode Simulated Annealing," Universitas AMIKOM, Yogyakarta, 2014.

[5] W. Cahyaningtyas, "Analisis Radio Frequency Channe Wireless Fidelity (WiFi) pada Performa 
Jaringan WiFi FTI UKSW: Studi Kasus WiFi FTI UKSW," Universitas Kristen Satya Wacana, Salatiga, 2017.

[6] P. Wulandari, S. Soim, and M. Rose, "Monitoring dan Analisis QoS (Quality of Service) Jaringan Internet pada Gedung KPA Politeknik Negeri Sriwijaya dengan Metode Drive Test," Prosiding SNATIF, vol. 4, pp. 342-347, 2017.

[7] A. Garnis, Suroso, and S. Solm, "Pengkajian Kualitas Sinyal dan Posisi WiFi Access Point dengan Metode RSSI di Gedung KPA Politeknik Negeri Sriwijaya," Prosiding SNATIF, vol. 4, pp. 429-434, 2017.

[8] R. Wulandari, "ANALISIS QoS (QUALITY OF SERVICE) PADA JARINGAN INTERNET (STUDI KASUS : UPT LOKA UJI TEKNIK PENAMBANGAN JAMPANG KULON - LIPI)," JuTISI, vol. 2, no. 2, Aug. 2016, doi: 10.28932/jutisi.v2i2.454.

\section{Authors' information}

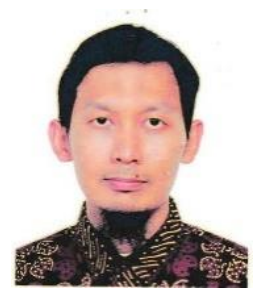

Widyasmoro obtained his B.Eng. in Electrical Engineering from Universitas Jenderal Soedirman, Indonesia in 2007. His Master study was done at 2009 at the Electrical Engineering, Asia University, Taiwan. He currently is a lecture in department of electrical engineering, Universitas Muhammadiyah Yogyakarta.

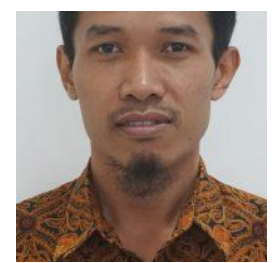

Kunnu Purwanto obtained his B.Eng. in Electrical Engineering from Universitas Muhammadiyah Yogyakarta, Indonesia in 2009. His Master study was done at 2015 at the Universitas Gadjah Mada, Indonesia. He currently is a lecture in department of electrical engineering, Universitas Muhammadiyah Yogyakarta

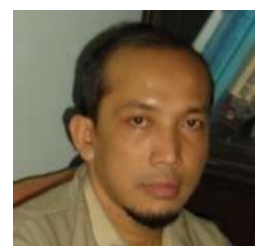

Ramadoni Syahputra obtained his B. Eng in Electrical Engineering from Universitas Muhammadiyah Yogyakarta, Indonesia in 1998. His Master study was done at 2002 at the Electrical Power Systems, Universitas Gadjah Mada, Indonesia. He got his Doctoral's degree in 2015 from Institut Teknologi Sepuluh Nopember, Surabaya. He currently is a lecture in department of electrical engineering, Universitas Muhammadiyah Yogyakarta

Dedy Prasetiyo obtained her B. Eng in Electrical Engineering from Universitas Muhammadiyah Yogyakarta, Indonesia in 2018.

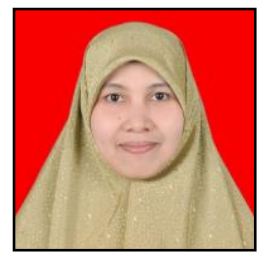

Yessi Jusman obtained her B.Eng. in Electrical and Electronic Engineering from Andalas University, Indonesia in 2007. She worked as a Research Assistant started in July 2008 until November 2009 in Universiti Sains Malaysia. Her Master study was done at 2012 at the School of Electrical and Electronic Engineering, USM Engineering
Campus in Nibong Tebal, Penang, Malaysia. She was finished her $\mathrm{PhD}$ degree at 2016 with specializes in Image, Signal Processing, and algorithms. She currently is a lecture in department of electrical engineering, Universitas Muhammadiyah Yogyakarta. 